\title{
Estimation of Tadalafil Using Derivative Spectrophotometry in Bulk Material and in Pharmaceutical Formulation
}

\author{
Zamir G. Khan, Amod S. Patil, and Atul A. Shirkhedkar \\ Department of Pharmaceutical Chemistry, R. C. Patel Institute of Pharmaceutical Education \& Research, Karwand Naka, \\ Shirpur, Dhule District, Maharashtra 425 405, India
}

Correspondence should be addressed to Atul A. Shirkhedkar; atulshirkhedkar@rediffmail.com

Received 17 January 2014; Accepted 2 May 2014; Published 21 May 2014

Academic Editor: Craig J. Eckhardt

Copyright (c) 2014 Zamir G. Khan et al. This is an open access article distributed under the Creative Commons Attribution License, which permits unrestricted use, distribution, and reproduction in any medium, provided the original work is properly cited.

\begin{abstract}
Four simple, rapid, accurate, precise, reliable, and economical UV-spectrophotometric methods have been proposed for the determination of tadalafil in bulk and in pharmaceutical formulation. "Method A" is first order derivative UV spectrophotometry using amplitude, "method B" is first order derivative UV spectrophotometry using area under curve technique, "method C" is second order derivative UV spectrophotometry using amplitude, and "method D" is second order derivative UV spectrophotometry using area under curve technique. The developed methods have shown best results in terms of linearity, accuracy, precision, and LOD and LOQ for bulk drug and marketed formulation as well. In N,N-dimethylformamide, tadalafil showed maximum absorbance at $284 \mathrm{~nm}$. For "method A" amplitude was recorded at $297 \mathrm{~nm}$ while for "method B" area under curve was integrated in the wavelength range of 290.60-304.40 nm. For "method C" amplitude was measured at $284 \mathrm{~nm}$ while for "method D" area under curve was selected in the wavelength range of $280.80-286.20 \mathrm{~nm}$. For methods A and B, tadalafil obeyed Lambert-Beer's law in the range of $05-50 \mu \mathrm{g} / \mathrm{mL}$ while for "methods C and D", tadalafil obeyed Lambert-Beer's law in the range of $20-70 \mu \mathrm{g} / \mathrm{mL}$, and-for "methods A, B, C, and D" the correlation coefficients were found to be > than 0.999 .
\end{abstract}

\section{Introduction}

Tadalafil (TD) is (6R,12aS)-6-(1,3-benzodioxol-5-yl)-2,3,6,7, 12,12a-hexahydro-2-methylpyrazino $\left[1^{\prime}, 2^{\prime}: 1,6\right]$ pyrido[3,4-b] indole-1,4-dione [1]. The chemical structure of tadalafil is shown in Figure 1. Tadalafil is a selective inhibitor of phosphodiesterase type 5 (PDE5) [2]. It is an impotence agent. It is indicated for the treatment of erectile dysfunction [3]. A detailed literature survey for tadalafil revealed that several analytical methods are reported for the determination of tadalafil by high-performance liquid-chromatography [4-8], high-performance thin-layer chromatography [9], spectrofluorimetry [10], and UV-spectrophotometry [11].

To our knowledge no methods were found in literature for determination of tadalafil in bulk and pharmaceutical formulation using derivative spectroscopic techniques. Therefore, our attempt is to develop first order and second order derivative spectroscopy using amplitude and also area under curve (AUC) techniques.

The AUC method is applicable where there is no sharp peak or when broad spectra are obtained. It involves the calculation of integrated value of area with respect to the wavelength between the two selected wavelengths $\lambda_{1}$ and $\lambda_{2}$. Selection of wavelength range is on the basis of repeated observations so as to get the linearity between AUC and concentration [12]. Further, methods were validated as per ICH guidelines [13].

\section{Experimental Work}

2.1. Material and Methods. Tadalafil working standard was obtained from Glenmark Pharmaceuticals Ltd., Mumbai, 


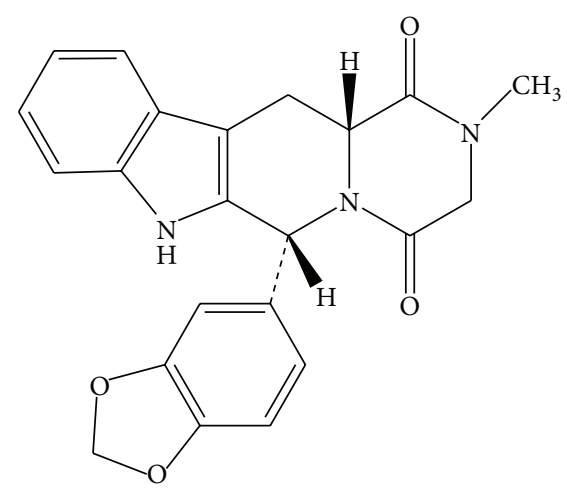

FIgURE 1: Chemical structure of tadalafil.

India. The marketed formulation (TADACIP) $20 \mathrm{mg}$ was purchased from local market. N,N-Dimethylformamide (DMF) (analytical grade) and R.O. water were used for the experiment.

2.2. Instrument. A double beam UV-VIS spectrophotometer (UV-2450, Shimadzu, Japan) connected to computer loaded with spectra manager software UV Probe 2.21 with $10 \mathrm{~mm}$ quartz cells was used. The spectra were obtained with the instrumental parameters as follows: wavelength range: 400$200 \mathrm{~nm}$; scan speed: medium; sampling interval: $1.0 \mathrm{~nm}$; band width $(\Delta \lambda): 1.0 \mathrm{~nm}$; spectral slit width: $1 \mathrm{~nm}$. An electronic balance (Model Shimadzu AUX 120) was used for weighing purpose.

\subsection{Preparation of Stock Standard Solution and Selection of} Wavelengths. The stock standard solution of tadalafil was prepared by dissolving accurately weighed $10 \mathrm{mg}$ in $50 \mathrm{~mL}$ of DMF. It was further diluted with water to obtain concentration of $40 \mu \mathrm{g} / \mathrm{mL}$ which was scanned in UV range 400-200 nm; tadalafil showed a maximum absorbance at $284 \mathrm{~nm}$. For "method A" amplitude in first order derivative spectrum was determined at $297 \mathrm{~nm}$ while for "method B" AUC in first order derivative spectrum was selected in between 290.60 and $304.40 \mathrm{~nm}$. In "method C" amplitude of second order derivative spectrum was recorded at $284 \mathrm{~nm}$ while in "method D" AUC of second derivative spectrum was selected in between 280.80 and $286.20 \mathrm{~nm}$.

The selection of wavelengths in all four methods is shown in Figure 2.

2.4. Methods $A$ and $B$. The zero order absorption spectra of tadalafil were derivatized in first order using software UV Probe 2.21 with delta lambda 4 and scaling factor 2. In "method A" the amplitudes were recorded at $297 \mathrm{~nm}$ while for "method B" area under curve between the two wavelengths 290.60 and $304.40 \mathrm{~nm}$ was selected. The calibration curves were constructed by plotting concentrations $05-50 \mu \mathrm{g} / \mathrm{mL}$ versus amplitude/AUC between selected wavelengths for "methods A and B," respectively.
2.5. Methods $C$ and $D$. The zero order absorption spectra of tadalafil was derivatized in second order using software UV Probe 2.21 with delta lambda 4 and scaling factor 2. In "method C" the amplitudes were recorded at $284 \mathrm{~nm}$ while in "method D" area under curve was recorded in between the two wavelengths 280.80 and $286.20 \mathrm{~nm}$. The calibration curves were constructed by plotting concentrations 20$70 \mu \mathrm{g} / \mathrm{mL}$ versus amplitude/AUC for "method C and D," respectively.

2.6. Preparation of Sample Solution. Ten tadalafil (TADACIP) tablets (label claim $20 \mathrm{mg}$ ) were weighed, transferred to a clean dry mortar, and grounded into a fine powder using a pestle. Tablet powder equivalent to $10 \mathrm{mg}$ of tadalafil was transferred to a $50 \mathrm{~mL}$ volumetric flask and $30 \mathrm{~mL}$ DMF was added. After ultrasonic vibration for $10 \mathrm{~min}$, volume was made up to be marked with DMF and filtered through Whatman filter paper (no. 41). From the filtrate, an appropriate volume was taken and diluted with water to get the final concentration of $20.0 \mu \mathrm{g} / \mathrm{mL}$ for "methods A and B" and $40.0 \mu \mathrm{g} / \mathrm{mL}$ for "methods C and D." The responses measured and concentrations in the sample were determined from respective linearity equation.

\section{Validation of Method}

The proposed method was validated as per ICH guidelines [13].

3.1. Linearity. The linearity of the "methods A and B" was evaluated by analysis of six standard solutions of tadalafil of concentrations $05,10,20,30,40$, and $50 \mu \mathrm{g} / \mathrm{mL}$ while for "methods C and D" linearity was evaluated by analysis of six standard solutions of tadalafil of concentrations 20, 30, 40, 50, 60 , and $70 \mu \mathrm{g} / \mathrm{mL}$.

3.2. Accuracy. The accuracy of all methods was evaluated by measurement of recovery. To the preanalyzed sample solutions $(10 \mu \mathrm{g} / \mathrm{mL}$ in methods $\mathrm{A}$ and $\mathrm{B}$ and $30 \mu \mathrm{g} / \mathrm{mL}$ in methods $\mathrm{C}$ and $\mathrm{D})$, known amounts of stock standard solutions were added at different levels, that is, $80 \%, 100 \%$, and $120 \%$. The solutions were reanalyzed by the proposed methods. The experiments were repeated for three times at each level for each method.

3.3. Precision. Precision of the methods was studied as intraday and inter-day variations. For "methods A and B," precision was determined by analyzing the 10,20 , and $40 \mu \mathrm{g} / \mathrm{mL}$ of tadalafil solutions as intra-day and inter-day variations. For "methods C and D," precision was determined by analyzing the 30,40 , and $60 \mu \mathrm{g} / \mathrm{mL}$ of tadalafil solutions as intra-day and inter-day variations.

3.4. Sensitivity. The sensitivity of measurements of tadalafil by the use of proposed methods was estimated in terms of limit of detection (LOD) and limit of quantification (LOQ) which were calculated using formulae "LOQ $=10 \times N / B$ " and "LOD $=3.3 \times N / B$," where " $N$ " is standard deviation of 


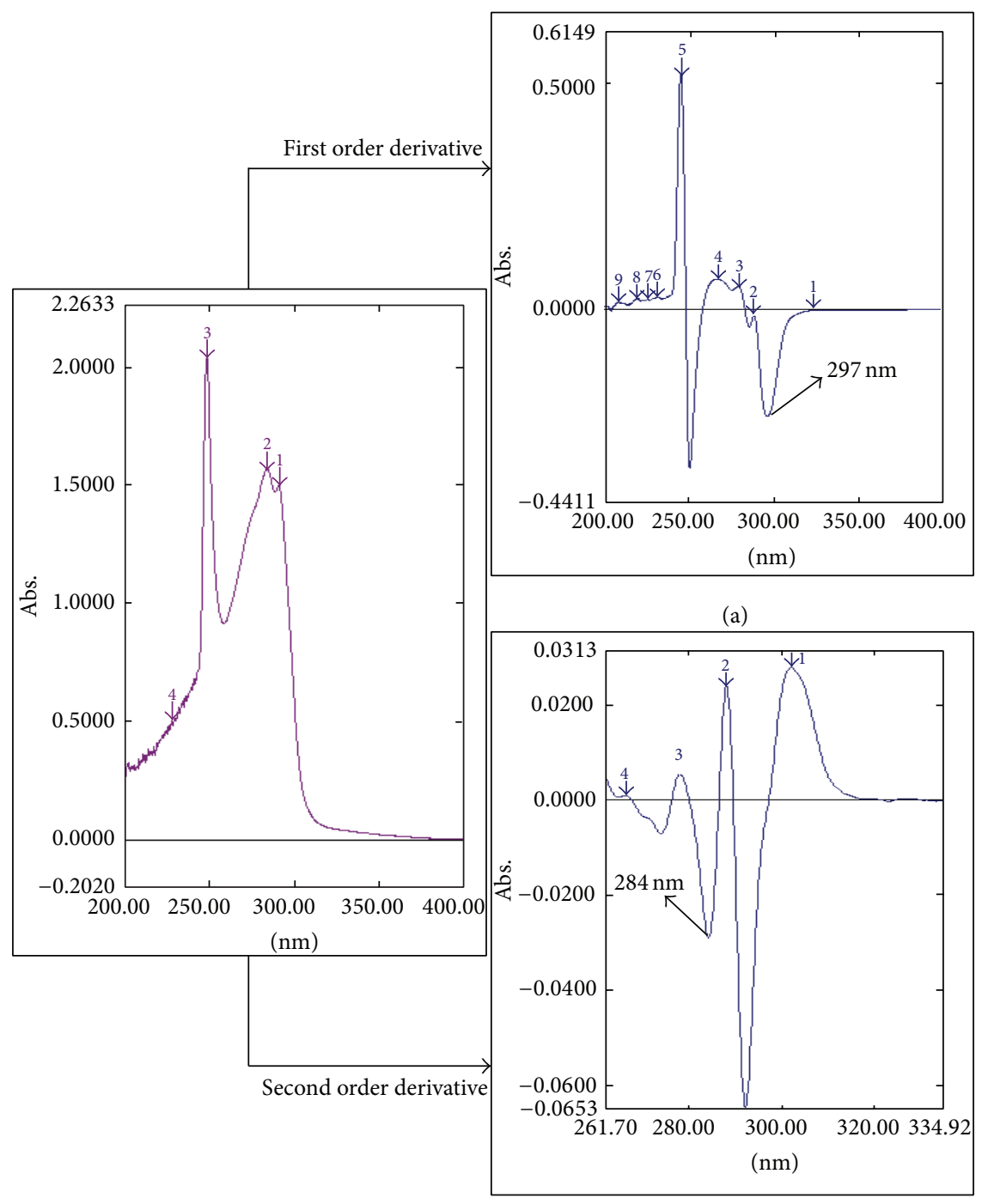

(c)

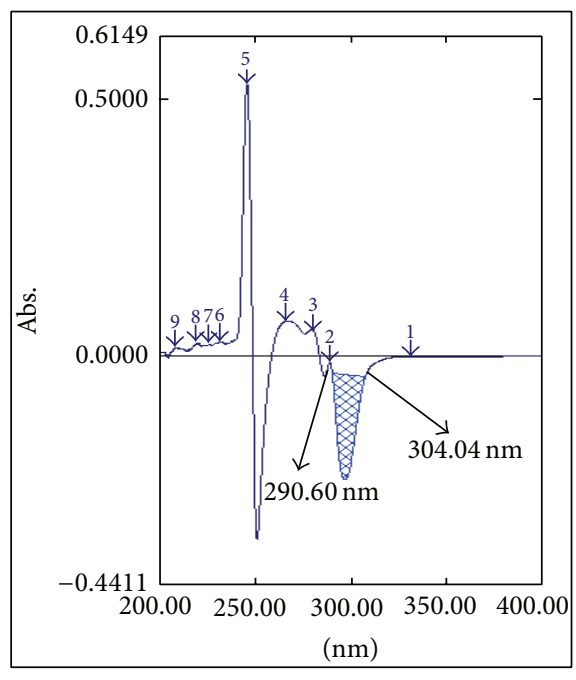

(b)

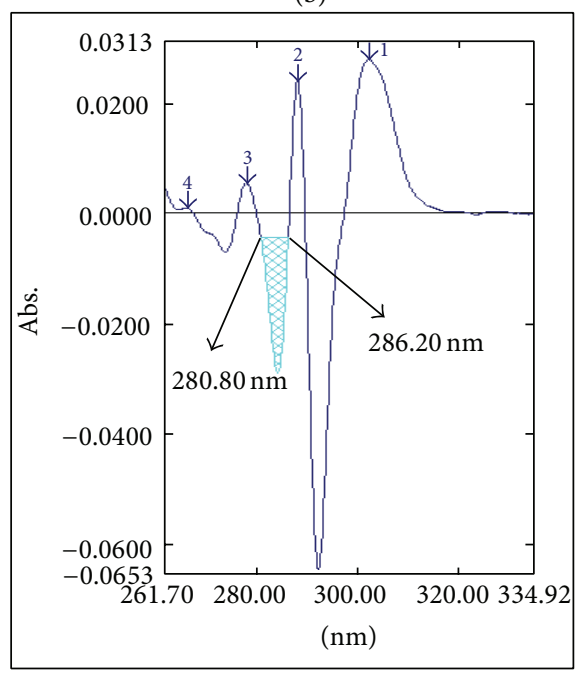

(d)

FIGURE 2: Zero order spectrum of tadalafil. (a) First order derivative spectrum. (b) First order derivative spectrum showing AUC between selected wavelengths. (c) Second order derivative spectrum. (d) Second order derivative spectrum showing AUC between selected wavelengths.

the amplitudes or peak areas of the tadalafil $(n=3)$, taken as a measure of noise, and " $B$ " is the slope of the corresponding calibration curve.

3.5. Repeatability. In "methods A and B," repeatability was determined by analyzing $20 \mu \mathrm{g} / \mathrm{mL}$ concentration of tadalafil while for "method C and D," it was studied by analyzing $40 \mu \mathrm{g} / \mathrm{mL}$ concentration of tadalafil solution for six times.

3.6. Ruggedness. For "methods A and B" ruggedness of the proposed method was determined by analyzing $20 \mu \mathrm{g} / \mathrm{mL}$ concentration of tadalafil while for "methods C and D" it was measured by analyzing $40 \mu \mathrm{g} / \mathrm{mL}$ concentration of tadalafil by two different analysts using similar operational and environmental conditions.

\section{Results and Discussion}

\subsection{Method Validation}

4.1.1. Linearity. From the linear regression data it is clear that for "methods A and B" calibration curves showed good linear relationship over the concentration range of $05-50 \mu \mathrm{g} / \mathrm{mL}$; similarly for "methods C and D" a good linear relationship was obtained over the concentration range $20-70 \mu \mathrm{g} / \mathrm{mL}$ for tadalafil. The data of regression analysis is shown in Table 1 .

4.1.2. Accuracy. The solutions were reanalyzed by proposed methods; results of recovery studies are reported in Table 2. The $\%$ RSD values that were determined and found to be less than 2 indicate that the method is accurate. 
TABLE 1: Optical characteristics of tadalafil.

\begin{tabular}{lcccc}
\hline Parameters & Method A & Method B & Method C & Method D \\
\hline Beer-Lambert's range $(\mu \mathrm{g} / \mathrm{mL})$ & $05-50$ & $05-50$ & $20-70$ & $20-70$ \\
$\lambda$ max $(\mathrm{nm}) /$ wavelength range $(\mathrm{nm})$ & 297 & $290.60-304.40$ & 284 & $280.80-286.20$ \\
Slope & 0.0064 & 0.0380 & 0.0013 & 0.0015 \\
Intercept & -0.0123 & -0.0269 & -0.0178 & 0.0151 \\
Correlation coefficient & 0.9993 & 0.9993 & 0.9990 & 0.9991 \\
\hline
\end{tabular}

TABLe 2: Accuracy studies.

\begin{tabular}{|c|c|c|c|c|c|c|}
\hline Drug & Methods & $\begin{array}{c}\text { Initial amount } \\
{[\mu \mathrm{g} / \mathrm{mL}]}\end{array}$ & $\begin{array}{c}\text { Amount added } \\
{[\mu \mathrm{g} / \mathrm{mL}]}\end{array}$ & $\begin{array}{c}\text { Amount recovered } \\
{[\mu \mathrm{g} / \mathrm{mL}, n=3]}\end{array}$ & $\%$ Recovered & $\%$ RSD \\
\hline \multirow{12}{*}{ Tadalafil } & \multirow{3}{*}{ A } & 10 & 8 & 18.07 & 100.91 & 0.52 \\
\hline & & 10 & 10 & 20.16 & 101.63 & 0.65 \\
\hline & & 10 & 12 & 22.13 & 101.11 & 0.47 \\
\hline & \multirow{3}{*}{ B } & 10 & 8 & 18.06 & 100.75 & 0.89 \\
\hline & & 10 & 10 & 20.10 & 101.06 & 1.22 \\
\hline & & 10 & 12 & 22.06 & 100.50 & 0.29 \\
\hline & \multirow{3}{*}{$\mathrm{C}$} & 30 & 24 & 54.13 & 100.54 & 0.18 \\
\hline & & 30 & 30 & 60.13 & 100.44 & 0.16 \\
\hline & & 30 & 36 & 66.06 & 100.16 & 0.19 \\
\hline & \multirow{3}{*}{$\mathrm{D}$} & 30 & 24 & 54.11 & 100.48 & 0.16 \\
\hline & & 30 & 30 & 60.10 & 100.35 & 0.12 \\
\hline & & 30 & 36 & 66.07 & 100.21 & 0.29 \\
\hline
\end{tabular}

$n$ : number of estimations.

TABle 3: Precision studies.

\begin{tabular}{|c|c|c|c|c|c|c|}
\hline Drug & Methods & $\begin{array}{c}\text { Concentration } \\
{[\mu \mathrm{g} / \mathrm{mL}]}\end{array}$ & $\begin{array}{c}\text { Intra-day } \\
{[n=3]}\end{array}$ & \% RSD & $\begin{array}{c}\text { Inter-day } \\
{[n=3]}\end{array}$ & $\%$ RSD \\
\hline \multirow{12}{*}{ Tadalafil } & \multirow{3}{*}{ A } & 10 & 9.93 & 0.32 & 9.95 & 0.31 \\
\hline & & 20 & 20.20 & 0.77 & 20.25 & 1.17 \\
\hline & & 40 & 40.71 & 0.10 & 40.66 & 0.07 \\
\hline & \multirow{3}{*}{ B } & 10 & 9.87 & 0.67 & 9.90 & 0.40 \\
\hline & & 20 & 20.03 & 0.06 & 20.05 & 0.13 \\
\hline & & 40 & 40.07 & 0.06 & 40.17 & 0.14 \\
\hline & \multirow{3}{*}{$\mathrm{C}$} & 30 & 30.08 & 0.12 & 30.33 & 1.32 \\
\hline & & 40 & 40.12 & 0.11 & 40.07 & 0.08 \\
\hline & & 60 & 60.07 & 0.07 & 60.11 & 0.11 \\
\hline & \multirow{3}{*}{$\mathrm{D}$} & 30 & 29.73 & 1.69 & 30.02 & 1.30 \\
\hline & & 40 & 39.91 & 0.94 & 39.68 & 1.41 \\
\hline & & 60 & 59.48 & 1.03 & 59.93 & 1.11 \\
\hline
\end{tabular}

$n$ : number of estimations.

TABLE 4: Repeatability studies.

\begin{tabular}{|c|c|c|c|c|c|c|}
\hline Drug & Methods & $\begin{array}{c}\text { Amount taken } \\
{[\mu \mathrm{g} / \mathrm{mL}]}\end{array}$ & $\begin{array}{l}\text { Amount found } \\
{[\mu \mathrm{g} / \mathrm{mL}]}\end{array}$ & $\begin{array}{c}\% \text { Amount found } \\
{[n=6]}\end{array}$ & Mean \pm SD & $\%$ RSD \\
\hline \multirow{4}{*}{ Tadalafil } & A & 20 & 20.15 & 100.75 & $100.75 \pm 1.06$ & 1.06 \\
\hline & B & 20 & 20.02 & 100.14 & $100.14 \pm 0.37$ & 0.37 \\
\hline & $\mathrm{C}$ & 40 & 40.30 & 100.76 & $100.76 \pm 0.86$ & 0.85 \\
\hline & $\mathrm{D}$ & 40 & 39.90 & 99.75 & $99.65 \pm 0.71$ & 0.70 \\
\hline
\end{tabular}

$n$ : number of estimations. 
TABLE 5: Ruggedness studies.

\begin{tabular}{|c|c|c|c|c|c|}
\hline \multirow{2}{*}{ Drug } & \multirow{2}{*}{ Methods } & \multicolumn{2}{|c|}{ Analyst I } & \multicolumn{2}{|c|}{ Analyst II } \\
\hline & & $\begin{array}{c}\% \text { Amount found } \pm \text { SD } \\
{[n=3]}\end{array}$ & \% RSD & $\begin{array}{c}\text { \% Amount found } \pm \text { SD } \\
{[n=3]}\end{array}$ & $\%$ RSD \\
\hline \multirow{4}{*}{ Tadalafil } & A & $101.27 \pm 0.90$ & 0.89 & $100.75 \pm 0.45$ & 0.44 \\
\hline & B & $100.55 \pm 0.18$ & 0.18 & $99.90 \pm 0.11$ & 0.11 \\
\hline & C & $101.47 \pm 0.40$ & 0.39 & $101.41 \pm 0.29$ & 0.28 \\
\hline & $\mathrm{D}$ & $99.05 \pm 0.58$ & 0.59 & $99.61 \pm 1.10$ & 1.11 \\
\hline
\end{tabular}

$n$ : number of estimations.

4.1.3. Precision. The precision of the developed methods was expressed in terms of \% relative standard deviation \% RSD. These results showed reproducibility of the assay. The \% RSD values were found to be less than 2 , so this indicates that the methods are precise for the determination of the tadalafil in pharmaceutical formulation. Results are shown in Table 3.

4.1.4. Sensitivity. The LOD and LOQ for tadalafil in "method A" were found to be $0.11 \mu \mathrm{g}$ and $0.33 \mu \mathrm{g}$ while in "method B" $0.15 \mu \mathrm{g}$ and $0.45 \mu \mathrm{g}$. Similarly in "method C" values for LOD and LOQ were as $0.50 \mu \mathrm{g}$ and $1.52 \mu \mathrm{g}$ and in "method D" $0.49 \mu \mathrm{g}$ and $1.49 \mu \mathrm{g}$.

4.1.5. Repeatability. For "methods A and B" repeatability was determined by analyzing $20 \mu \mathrm{g} / \mathrm{mL}$ concentration of tadalafil while for "method C and D" repeatability was determined by analyzing $40 \mu \mathrm{g} / \mathrm{mL}$ concentration of tadalafil solution for six times with \% RSD values $<2$ for all the methods. Results are shown in Table 4.

4.1.6. Ruggedness. Ruggedness was determined for solutions of tadalafil. The results are in acceptable range that is \% RSD values $<2$ for all the methods as shown in Table 5 . The results showed no statistical differences between different operators suggesting that the developed methods are rugged.

4.2. Analysis of Tablet Formulation. The amounts of tadalafil estimated from tablet formulation using methods A, B, C, and $\mathrm{D}$ were found to be $99.32 \%, 100.18 \%, 99.61 \%$, and $99.81 \%$, respectively. The $\%$ amount estimated from tablet formulation indicates that there is no interference from excipients present in it.

\section{Conclusion}

All four methods were developed for the determination of tadalafil based on different analytical techniques, UVspectrophotometric derivative, and AUC methods. The methods were validated and found to be simple, sensitive, accurate, and precise. Hence, the methods can be used successfully for routine analysis of pharmaceutical dosage form of tadalafil. The proposed spectrophotometric methods will not be substituted to the existing known methods available for the analysis of tadalafil. However, it can serve as an option where advanced instruments (e.g., HPLC) are not available for routine analysis.

\section{Conflict of Interests}

The authors declare that there is no conflict of interests regarding the publication of this paper.

\section{Acknowledgment}

The authors are thankful to the Principal, R. C. Patel Institute of Pharmaceutical Education and Research, Shirpur, 425405 (MS), India, for providing the laboratory facility.

\section{References}

[1] J. Maryadele and O. Neil, The Merck Index: An Encyclopedia of Chemicals, Drugs and Biologicals, Merck Research Laboratories, Division of Merck and Co., Whitehouse station, NJ, USA, 2006.

[2] S. C. Sweetman, Martindale: The Complete Drug Reference, Pharmaceutical Press, London, UK, 2007.

[3] M. Gupta, A. Kovar, and B. Meibohm, "The clinical pharmacokinetics of phosphodiesterase-5 inhibitors for erectile dysfunction," Journal of Clinical Pharmacology, vol. 45, no. 9, pp. 987-1003, 2005.

[4] D. V. S. Rao, P. Radhakrishnanand, and V. Himabindu, "Stress degradation studies on tadalafil and development of a validated stability-indicating LC assay for bulk drug and pharmaceutical dosage form," Chromatographia, vol. 67, no. 1-2, pp. 183-188, 2008.

[5] M. Sankar and S. Arulantony, "A stability indicating RP-HPLC method for the estimation of tadalafil in oral jelly dosage forms," Indian Journal of Medical Research, vol. 2, no. 8, pp. 19-22, 2013.

[6] P. B. Reddy, K. A. Reddy, and M. S. Reddy, "Validation and stability indicating RP-HPLC method for the determination of tadalafil API in pharmaceutical formulations," Research in Pharmaceutical Biotechnology, vol. 2, no. 1, pp. 001-006, 2010.

[7] N. Kannappan, D. Yada, D. Yada, and M. R. Shashikanth, "Method development and validation of stability indicating methods for assay of Tadalafil and Sildenafil citrate by HPLC," International Journal of ChemTech Research, vol. 2, no. 1, pp. 329-333, 2010.

[8] M. M. Mathpati, J. N. Sangshetti, V. P. Rane, K. R. Patil, and D. B. Shinde, "Stability-indicating LC method for determination of tadalafil in bulk drug and pharmaceutical dosage form," Chemia Analityczna, vol. 54, no. 4, pp. 679-689, 2009. 
[9] S. A. Patel and N. J. Patel, "High performance thin layer chromatographic method for determination of Tadalafil in tablet dosage form," The American Journal of PharmTech Research, vol. 1, no. 3, pp. 138-146, 2011.

[10] A. Kavitha, D. VijayaDurga, S. HimaBindu, K. Eshvendar, N. P. Khaleel, and D. Ani Kumar, "Forced degradation studies, quantification and in-vitro dissolution studies of Tadalafil by spectrofluorimetry," Asian Journal of Pharmaceutical and Clinical Research, vol. 6, no. 2, pp. 326-329, 2013.

[11] M. Yunoos, D. Gowri Sankar, B. Pragati Kumar, and S. Hameed, "UV spectrophotometric method for the estimation of tadalafil in bulk and tablet dosage form," E-Journal of Chemistry, vol. 7, no. 3, pp. 833-836, 2010.

[12] S. S. Chalikwar, A. A. Shirkhedkar, M. A. Bagul, P. S. Jain, and S. J. Surana, "Development and validation of zero and first order derivative: area under curve spectrophotometric methods for the determination of Entacapone in bulk material and in tablets," Pharmaceutical Methods, vol. 3, no. 1, pp. 14-17, 2012.

[13] "Validation of analytical procedures: text and methodology," ICH-Guidelines Q2 (R1), 2005. 

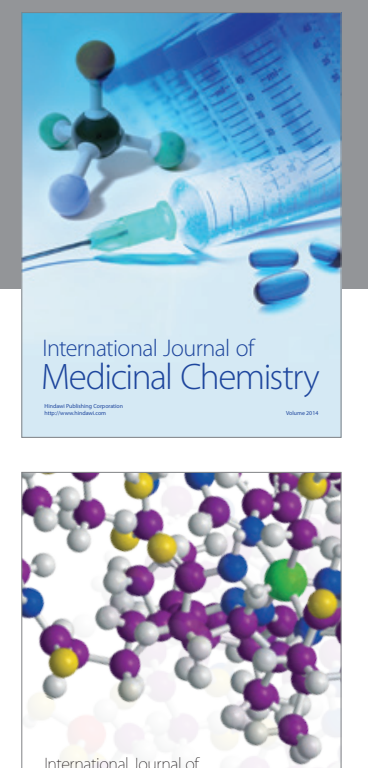

\section{Carbohydrate} Chemistry

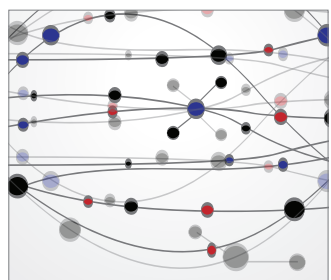

The Scientific World Journal
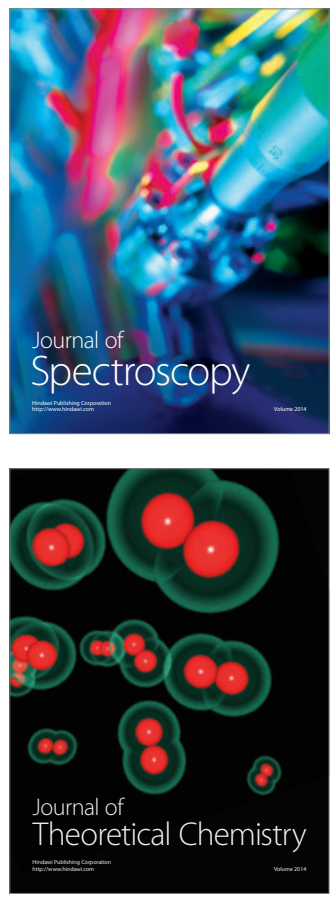
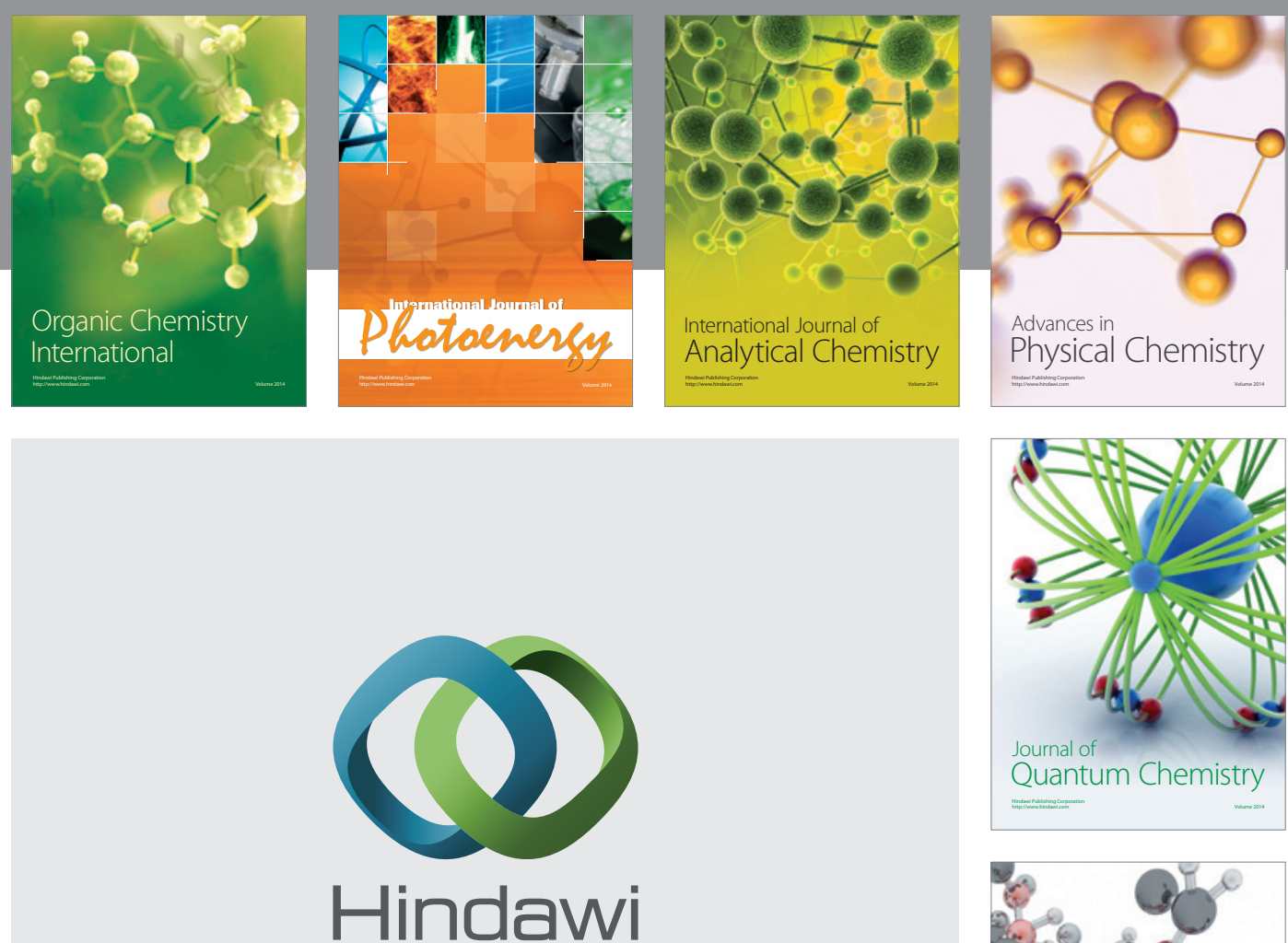

Submit your manuscripts at

http://www.hindawi.com

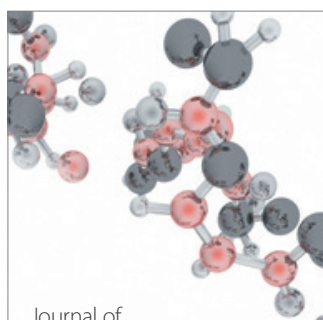

Analytical Methods

in Chemistry

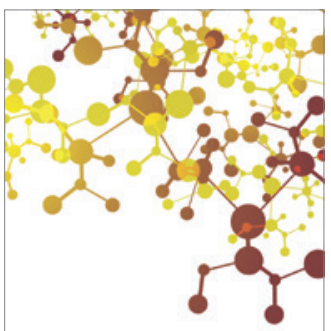

Journal of

Applied Chemistry

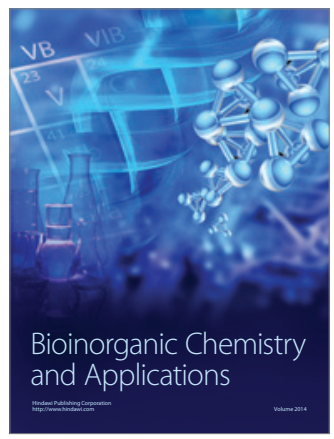

Inorganic Chemistry
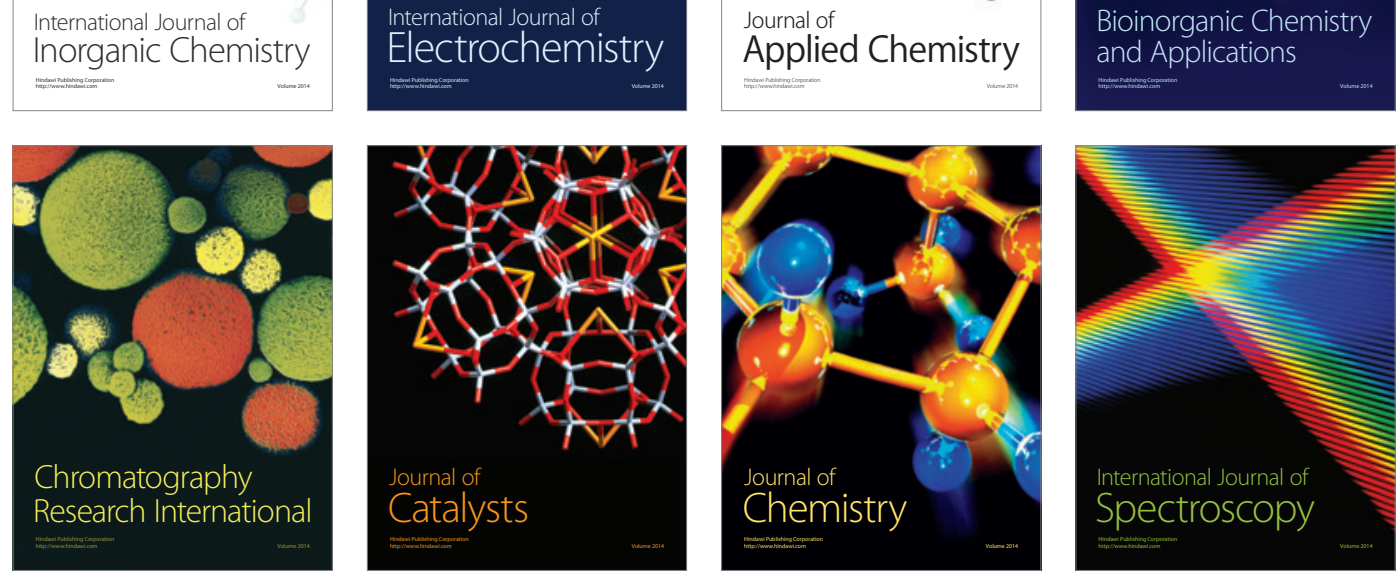